\title{
ACOMPANHAMENTO DAS ALTERAÇÕES NO ARMAZENAMENTO E CARACTERIZAÇÃO DOS FRUTOS DE BANANA (MUSA CAVENDISHII, variedade NANICA)
}

\author{
I. M. GUERRERO ${ }^{1}$, L. M. RAYO MENDEZ ${ }^{1}$ e A. V. GÓMEZ ${ }^{1}$ \\ ${ }^{1}$ Universidade de São Paulo, Escola Politécnica, Departamento de Engenharia Química, \\ Laboratório de Engenharia de Alimentos (LEA) \\ E-mail para contato: analiag_lea@usp.br
}

\begin{abstract}
RESUMO - A composição química da banana passa por grandes mudanças durante o amadurecimento, devido ao seu processo fisiológico do padrão respiratório climatério. Dependendo do seu uso, há um grande interesse nos estágios de maturação para permitir o aproveitamento das suas características, especialmente dos componentes com propriedades funcionais para o corpo humano, como os polissacarídeos não-amiláceos nas bananas maduras. $\mathrm{O}$ objetivo desse trabalho foi estabelecer e padronizar os parâmetros físico-químicos e de firmeza necessários para obter um purê de banana homogêneo, que contribuirá como matéria prima para uma extração de polissacarídeos não-amiláceos e sua utilização como ingrediente funcional. Bananas da var. Nanicão foram adquiridas comercialmente no estágio de maturação 1 (verdes) e armazenadas em temperatura ambiente até maturação completa. Durante este período, foram realizadas análises diários de firmeza, $\mathrm{pH}$, sólidos solúveis, acidez titulável e umidade. Verificou-se que a firmeza é um bom parâmetro para a avaliação dos estágios de maturação, uma vez que mostrou um comportamento decrescente conforme a banana amadurecia $(33,8$ $\pm 1,7$ até $1,5 \pm 0,2 \mathrm{~N}$ ). Os sólidos solúveis, a acidez e o $\mathrm{pH}$ variaram de forma não regular. Todas as análises físico-químicas foram comparadas com a literatura, estabelecendo que o estágio 7 de maturação cumpre com as características necessárias para a obtenção de um purê de banana homogéneo e uma posterior extração dos polissacarídeos não-amiláceos.
\end{abstract}

\section{INTRODUÇÃO}

A banana é uma das frutas mais consumidas e comercializadas mundialmente, com grande produção em países de clima tropical. É um fruto de grande importância na alimentação devido à presença de vitaminas $\mathrm{A}, \mathrm{B} 6 \mathrm{e} \mathrm{C}$, minerais e baixo teor de gorduras, além de ser uma boa fonte de energia para o organismo humano com boa digestibilidade, podendo ser consumida verde ou madura, crua ou processada (EMBRAPA, 2008).

Mundialmente as variedades mais produzidas são a Prata Comum, Prata Anã, Maçã, Mysoure, Terra, Nanica e Nanicão do subgrupo (Musa Cavendishii), sendo que esta última se destaca no âmbito de importações devido a características como tamanho, forma, sabor e aroma. Atualmente, o Brasil é considerado o quinto maior produtor mundial de banana, com um destaque da produção na região Nordeste (FAO, 2010). As variedades de grande destaque 
no Brasil são a Prata e a Pacovan, e em menor proporção a Prata Anã, Nanica, Nanicão, dentre outras (EMBRAPA, 2008).

A partir da colheita, a banana passa por 8 estágios de maturação, de verde até chegar numa coloração amarelada. A partir do estágio 5, surgem manchas negras variando de pequenas até grandes. No estágio 1 (verde) a banana caracteriza-se pelo baixo teor de açúcares, alto teor de amido e pela adstringência devida aos componentes fenólicos da polpa. Conforme ela amadurece ao longo do tempo, o amido começa a sofrer hidrólise, os açúcares solúveis passam a se concentrar e há redução da adstringência e amaciamento da polpa (textura). Paralelamente, na casca ocorre a degradação da clorofila, pigmento que confere a coloração esverdeada a esta, e, por consequência, observa-se o amarelecimento da cor, devido à síntese de pigmentos carotenoides. A cor da casca é um bom indicativo do grau de amadurecimento da banana, sendo o principal critério para a colheita, aliado à idade do cacho (EMBRAPA, 2008).

Devido a fatores como nutrientes, simplicidade no consumo, higiene e proteção natural oferecida pela casca, a banana é um fruto de imensa aceitação (MEDINA et al., 1978). A Tabela 1 apresenta a composição centesimal da banana nanica "in natura". Em relação ao conteúdo calórico, a banana é um alimento altamente energético com cerca de 110 calorias por porção (fruta de tamanho médio de 126 g) (NEPA, 2011).

Tabela 1 - Composição centesimal (\%) da banana Nanica (NEPA, 2011).

\begin{tabular}{ll}
\hline Componentes químicos & Teor $(\%)$ \\
\hline Água & 73,8 \\
Carboidrato & 23,8 \\
Colesterol & 0 \\
Fibra Alimentar & 1,9 \\
Lipídeos & 0,1 \\
Proteína & 1,4 \\
\hline
\end{tabular}

A banana possui uma boa quantia de carboidratos de fácil assimilação, divididos em os facilmente digeríveis, que proporcionam energia ao corpo, e aqueles resistentes à digestão, que atuam como fibra alimentar e ação prebiótica, por fornecer benefícios à saúde intestinal (CUMMINGS et al., 2007). Entre os não digeríveis estão os polissacarídeos não amiláceos (PNAs) presentes na banana madura (estágio 8). Deste modo o isolamento de PNAs de diferentes tipos de plantas, frutos e grãos tem sido objeto de estudo por vários autores, para serem usados como ingredientes funcionais na dieta humana (CORDENUNSI et al., 2008; CHEN et al., 2012; FAN et al., 2010).

Esse trabalho forma parte da primeira etapa de um projeto de pesquisa visando extrair PNAs da polpa de banana madura para serem adicionados como ingrediente funcional em preparações alimentícias. Assim, o objetivo foi estabelecer e padronizar os parâmetros físicoquímicos e de firmeza da matéria prima em relação ao grau de maturação adequado para obter um purê de banana homogêneo que permita uma extração de PNAs com alto rendimento.

\section{METODOLOGIA}




\subsection{Matérias primas}

Foram utilizadas bananas verdes variedade Nanicão (Musa Cavedishii), procedentes da região do Vale da Ribeira, SP, no estágio 1 de maturação, ou seja, adquiridas após um dia de colheita e não submetidas à câmara de maturação. Os frutos foram previamente selecionados pelo mesmo fornecedor no CEAGESP - Companhia de Entrepostos e Armazéns Gerais do Estado de São Paulo, da cidade de São Paulo, de forma de atenderem as especificações determinadas.

\subsection{Processo de obtenção de purê de banana}

As bananas foram separadas e mantidas à temperatura de $25 \pm 2{ }^{\circ} \mathrm{C}$ numa sala climatizada. O armazenamento das bananas foi monitorado ao longo do período de armazenamento até 14 dias após a colheita para análise do estágio de maturação.

As bananas maduras (estágio 8) foram higienizadas com água clorada (200 ppm) por 10 min, para a limpeza das impurezas e desinfecção das mesmas. Em seguida, foram descascadas e fatiadas manualmente, com ajuda de facas, em rodelas de $4 \mathrm{~mm}$ de espessura. Imediatamente as fatias foram imersas por $5 \mathrm{~min}$ em solução de ácido cítrico $(1 \mathrm{~g} / \mathrm{L})$ para retardar o escurecimento enzimático. Após da eliminação do excesso de água, as rodelas foram amassadas num liquidificador para obter o purê de banana.

Os frutos inteiros foram caracterizados através da realização de análises de firmeza e o purê de banana através do teor de umidade, teor de sólidos solúveis, $\mathrm{pH}$ e acidez titulável.

\subsection{Análises de caracterização da matéria-prima}

Análises Físico Químicas

- pH: Medido utilizando o pH-Stat (RADIOMETER, mod PHM290, França), segundo o método de ZENEBON e PASCUET (2005).

- Umidade: Determinada através do método gravimétrico, em amostras de purê de banana de 3-5 g (ZENEBON, PASCUET, 2005). A mostra foi aquecida em estufa (MARCA MARCONI, mod MA-030, Brasil) a $70^{\circ} \mathrm{C}$, com vácuo de 13,3 $\mathrm{kPa}$, até obter peso constante.

Cálculo:

$(100 \times \mathrm{N}) / \mathrm{P}=$ Umidade por cento $\mathrm{m} / \mathrm{m}$

$\mathrm{N}=$ perda de peso em $\mathrm{g}$

$\mathrm{P}=$ massa de amostra em $\mathrm{g}$

- Teor de Sólidos Solúveis: Determinado por medição direta usando o Refratômetro (CARL-ZEISS JENA, mod 711849, Alemanha) e corrigido em relação a acidez titulável e a temperatura de acordo com ZENEBON e PASCUET (2005).

- Acidez titulável: Determinada de acordo com o método volumétrico 310/IV (ZENEBON e PASCUET, 2005). Amostras de $10 \mathrm{~g}$ de purê de banana foram homogeneizadas em frasco Erlenmeyer com $100 \mathrm{~mL}$ de água destilada e tituladas com solução de hidróxido de sódio $0,1 \mathrm{M}$. 
Cálculo:

$(V \times f \times M \times 100) / P=$ Acidez em $m L$ de solução M por cento $v / m$

$\mathrm{V}=\mathrm{n}^{\mathrm{o}}$ de $\mathrm{mL}$ da solução de hidróxido de sódio gasto na titulação

$\mathrm{f}=$ fator de correção da solução de hidróxido de sódio

$\mathrm{P}=$ massa da a mostra em $\mathrm{g}$

$\mathrm{M}=$ molaridade da solução de hidróxido de sódio

Firmeza: A firmeza foi determinada nos frutos inteiros descascados, usando o Texturômetro Texture Analyzer TA-53 XT2i plus (SMS, Inglaterra), sob compressão de um cilindro de aço com $6 \mathrm{~mm}$, em teste de penetração. A firmeza foi definida como a força máxima obtida medida em Newtons $(\mathrm{N})$ da curva força-tempo (DITCHFIELD, TADINI, 2002).

Todas as determinações foram realizadas em triplicata. $\mathrm{O}$ resultado final foi considerado como o valor médio entre as repetições.

\section{RESULTADOS E DISCUSSÃO}

\subsection{Firmeza}

Na Figura 1 é apresentada a evolução do amadurecimento da banana ao longo do período de armazenamento.

Figura 1 - Evolução da Firmeza da banana ao longo do armazenamento

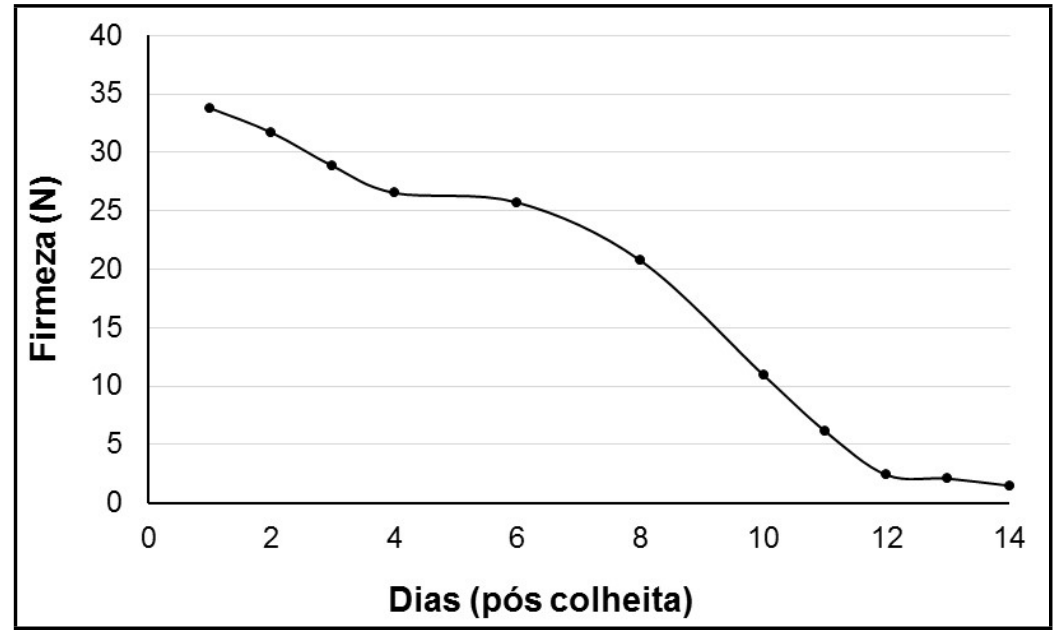

Observou-se um decrescimento da firmeza com o decorrer dos dias, esse fenômeno está relacionado à hidrolise do amido durante a maturação em açúcares pela ação conjunta de algumas enzimas, ou seja, carboidratos de cadeias menores e de estrutura menos rígidas, ao contrário do amido, polissacarídeo de estrutura mais rígida. No início da maturação, a banana possui uma quantidade de amido consideravelmente maior que a de açúcares, o que oferece a banana verde uma firmeza notavelmente maior, enquanto que, ao passo em que ela vai 
amadurecendo, a quantidade de açúcares tende a aumentar concomitantemente com o decrescimento da presença de amido, o que diminui progressivamente a firmeza da banana e lhe oferece uma textura mais macia e flexível. A firmeza do fruto também é comprometida pela degradação das pectinas ocasionada pela ação das enzimas poligalacturase e pectinesterase (MUSTAFFA et al., 1998; TRIBESS, 2009).

\subsection{Caracterização físico-química}

Os resultados das análises físico-químicas e caracterização da banana madura são apresentados na Tabela 2, os resultados foram comparados com dados obtidos por DITCHFIELD, TADINI (2002) e OLIVEIRA (2007).

Tabela 2 - Umidade, sólidos solúveis ( $\left.{ }^{\circ} \mathrm{Brix}\right), \mathrm{pH}$, acidez titulável e firmeza do purê de banana, comparadas com dados da literatura.

\begin{tabular}{lll}
\hline Ensaio & Resultado & Dados da literatura \\
\hline Umidade (\%) & $75,39 \pm 0,20$ & $75,26 \pm 0,01^{\mathrm{a}}$ \\
Sólidos Solúveis $\left({ }^{\circ}\right.$ Brix) & $23,29 \pm 0,25$ & $23,17 \pm 0,14^{\mathrm{a}}$ \\
pH & $5,28 \pm 0,08$ & $5,199^{\mathrm{b}}$ \\
Acidez titulável (\%) & $4,54 \pm 0,15$ & $3,471^{\mathrm{b}}$ \\
Firmeza (N) & $1,47 \pm 0,19$ & $1,53^{\mathrm{b}}$ \\
\hline
\end{tabular}

${ }^{a}$ OLIVEIRA (2007)

b DITCHFIELD, TADINI (2002)

$\mathrm{Na}$ Tabela 2 observa-se uma semelhança dos resultados obtidos com os dados da literatura. Segundo OLIVEIRA (2007) os valores encontrados de umidade $(75,26 \pm 0,01)$ e sólidos solúveis $(23,17 \pm 0,14)$ correspondem às bananas em fase "F3", estágio de coloração da casca amarela bastante forte, sendo a textura da polpa extremadamente macia e o sabor muito doce. DITCHFIELD, TADINI (2002) e TRIBESS (2009), avaliaram as características físicoquímicas de bananas da variedade Nanicão nos oito estágios de maturação, concluindo que o melhor método para determinação do estágio de maturação da banana é a firmeza medida através de um texturômetro, expressa como força $(\mathrm{N})$. Os valores bibliográficos de $\mathrm{pH}$, acidez titulável e firmeza (DITCHFIELD, TADINI, 2002) apresentados na Tabela 2 correspondem ao estágio 7 de maturação. De acordo com o valor de firmeza obtido nos ensaios de textura $(1,47 \pm 0,19)$ pode-se concluir que as bananas analisadas encontravam-se no estágio 7 de maturação.

\section{CONCLUSÕES}

A banana passa por grandes mudanças durante o processo de amadurecimento que podem ser observadas pelas mudanças nos parâmetros medidos nos ensaios realizados. $\mathrm{O}$ melhor parâmetro para determinar o estágio de maturação da banana é a firmeza da banana. $\mathrm{O}$ pH e a acidez titulável não são bons parâmetros pois apresentam valores semelhantes nos estágios iniciais e finais de maturação (DITCHFIELD, TADINI, 2002; TRIBESS, 2009). Portanto, para conseguir padronizar a matéria-prima é fundamental realizar a caracterização físico-química e de textura da banana. É de ressaltar que o conhecimento e padronização da matéria prima é fundamental para o processo de extração dos polissacarídeos não amiláceos 
devido a que o rendimento final se verá afetado pelo estagio de maturação, pela concentração de açucares e a diminuição do amido nas bananas durante seu amadurecimento.

\section{REFERÊNCIAS BIBLIOGRÁFICAS}

CHEN, R.; LI, Y.; DONG, H.; LIU, Z.; LI, S.; YANG, S.; LI, X. Optimization of ultrasonic extraction process of polysaccharides from Ornithogalum Caudatum Ait and evaluation of its biological activities. Ultrasonics Sonochemistry, v. 19, p. 1160-1168, 2012.

CORDENUNSI, B. R.; MISUZU SHIGA, T.; LAJOLO, F. Non-starch polysaccharide composition of two cultivars of banana (Musa acuminata L.: cvs Mysore and Nanicão). Carbohydrate Polymers, v. 71, p. 26-31, 2008.

CUMMINGS, J. H.; STEPHEN, A. M. Carbohydrate terminology and classification. European Journal of Clinical Nutrition, v. 61, n. 1, p. 5-18, 2007.

DICHFIELD, C.; TADINI, C. C. Acompanhamento do processo de amadurecimento da banana Nanicão (Musa cavendishii Lamb.). In: XVIII Congresso Brasileiro de Ciência e Tecnologia de Alimentos, 2002. Porto Alegre. Disponível em http://sites.poli.usp.br/pqi/lea/docs/cbcta2002h.pdf. Acesso em Janeiro de 2015.

EMBRAPA. Empresa Brasileira de Pesquisa Agropecuária. Banana. 2008. Disponível em http://www.agencia.cnptia.embrapa.br/Agencia40/AG01/Abertura.html. Acesso em Janeiro de 2015.

ENGLYST, H. N.; HUDSON, G. J. The classification and measurement of dietary carbohydrates. Food Chemistry, v. 57(1), p. 15-21, 1996.

FAN, H.; MAZZA, G.; LIAO, X. Purification, composition and antioxidant activity of polysaccharides from wolfberry, cherry, kiwi and cranberry fruits. Croatian Journal of food Science and Technology, v. 2(1), p. 9-17. 2010.

FAO. Food and Agriculture Organization of the United Nations, FAOSTAT statistic database, 2010. Disponivel em http://faostat.fao.org. Acesso em Novembro de 2014.

MEDINA, J. C.; BLEINROTH, E. W.; MARTIN, Z. J.; TRAVAGLINI, D. A.; OKADA, M.; QUAST, D. G.; HASHIZUME, T.; RENESTO, O. V.; MORETTI, V. A. Banana: da cultura ao processamento e comercialização. $3^{\text {a }}$ edição. Campinas (SP), ITAL: p. 197, 1978.

MUSTAFFA, R.; OSMAN, A.; YUSOF, S.; MOHAMED, S. Physico-chemical changes in Cavendish banana (Musa cavendishii L var Montel) at different positions within a bunch during development and maturation. Journal of Food Science and Agriculture, v. 78, p. 201-207, 1998.

NEPA - NÚCLEO DE ESTUDOS E PESQUISAS EM ALIMENTAÇÃO. Tabela brasileira de composição de alimentos. NEPA-Unicamp, Campinas (SP), 105p, 2011.

OLIVEIRA, M. Efeito da composição química, origem e grau de maturação sobre a cor e a crocância da banana nanica obtida por secagem HTST. 111 f. Dissertação (Mestrado em Engenharia de Alimentos) - Faculdade de Engenharia de Alimentos, Universidade Estadual de Campinas, Campinas, 2007.

TRIBESS, T. B. Processo de obtenção de farinha de banana verde com alto conteúdo de amido resistente. 76 f. Tese (Doutorado em Engenharia Química) - Escola Politécnica, Universidade de São Paulo, São Paulo, 2009.

ZENEBON, O.; PASCUET, N. S. Métodos físico-químicos para análises de alimentos do Instituto Adolfo Lutz. 4 ed, Brasília: IAL - Instituto Adolfo Lutz, p. 1018, 2005. 